\title{
Synergistic Catalysis: Highly Enantioselective Cascade Reaction for the Synthesis of Dihydroacridines
}

\begin{abstract}
Sara Meninno, ${ }^{[a]}$ Marta Meazza,,$^{[a] *}$ Jung Woon Yang, Rios $^{[a] *}$

Abstract: We report the first stereoselective synthesis of dihydroacridines through synergistic catalysis, achieving the final target compounds with good to excellent yields and good to excellent enantioselectivities and diastereoselectivities. The synergistic approach consists in an activation of substituted quinolines with a Lewis acid catalyst that react in a cascade fashion with enals activated in the iminium form. Mechanistic calculations support the consecutive Michael-aldol reaction, followed by dehydration.
\end{abstract}

Acridine was first identified by Grebe and Caro as an impurity of anthracene isolated from coal tar. ${ }^{[1]}$ The development of orange Dye (1895) ${ }^{[2]}$ and the discovery of acriflavine ${ }^{[3]}$ are two of the most important milestones of the early history of acridines. ${ }^{[4]}$ Their application as antiseptics and antibacterials during the World War II was of paramount importance until their replacement by penicillins and antibiotics. Acridines present a large number of fascinating properties ranging from antibacterial, ${ }^{[5]}$ to anticancer ${ }^{[6]}$ without missing their use as dyes or sensors for biological or technical purposes. ${ }^{[7]}$ For example, Amsacrine [N-(4-(acridin-9ylamino)-3-methoxyphenyl)methanesulfonamide] $\mathbf{1}$ is an antineoplastic agent for the treatment of acute leukemia, Ledakrin $\mathbf{2}$ is an antitumor agent and the old Acriflavine $\mathbf{3}$ has been used as a topical antiseptic as well as antibacterial and anticancer agent. Partially saturated acridine derivatives like 1,2,3,4tetrahydroacridines also shown interesting properties: for example, Tacrine $\mathbf{4}$ has been used as a cholinesterase inhibitor for the treatment of Alzheimer (Figure 1). ${ }^{[8]}$

Despite these promising properties of acridines and derivatives, few methodologies have been reported for their synthesis, and almost none of them for the enantioselective synthesis of chiral dihydroacridines.

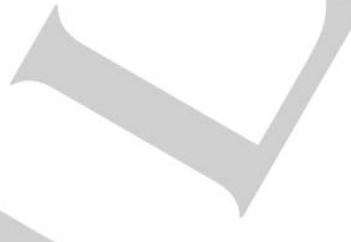

[a] Dr S. Meninno, Dr M. Meazza, Dr R. Rios

School of Chemistry, University of Southampton Highfield Campus, SO17 1BJ, Southampton, UK E-mail:m.meazza@soton.ac.uk rrt1f11@soton.ac.uk

[b] Prof. J. W. Yang

Department of Energy Science, Sungkyunkwan University Suwon 16419, Republic of Korea

[c] Prof. T. Tejero

Instituto de Sintesis Quimica y Catalisis Homogenea (ISQCH).

Universidad de Zaragoza-CSIC. Zaragoza, 50009. Spain

[d] Prof. P. Merino

Instituto de Biocomputación y Fisica de Sistemas Complejos (BIFI). Universidad de Zaragoza. Zaragoza, 50009. Spain

Supporting information for this article is given via a link at the end of the document.

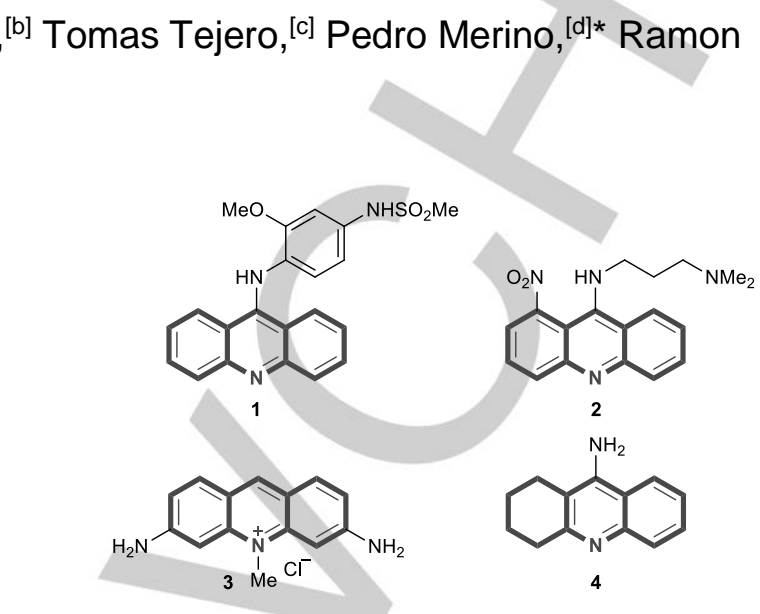

Figure 1. Examples of biologically active acridine derivatives.

The most classical approach for the preparation of acridine derivatives are the ring closure reactions leading to the synthesis of the central pyridine ring. For example, 2-aminoaryl ketones react with arynes generated "in situ" to form acridines in good yields (Scheme 1). ${ }^{[9]}$

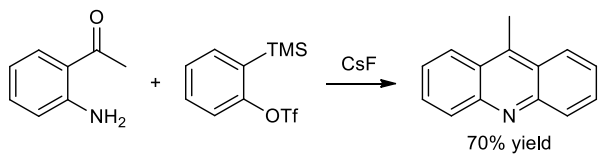

Scheme 1. Example of synthesis of acridines.

Acridines and dihydroacridines represent an interesting 3D scaffold to develop new libraries for pharma- and agrochemical industries. One of the main issues of acridines is their poor solubility and selectivity. To overcome these constraints, we speculated that the increase of $\mathrm{sp}^{3}$-carbons in the structure of the acridine enables us to improve the pharmacokinetic properties, such as solubility, which is predicted by Lovering when introducing the concept of "escape the flatland". ${ }^{[10]}$ At the same time, the presence of chiral centers could increase the selectivity of the compounds. We envisioned an effective synergistic catalysis approach for the synthesis of dihydroacridines, based on our previous works on the activation of heterocycles ${ }^{[11]}$ and the previous work of Prof K. A. Jørgensen on the activation of quinoline and their derivatives (Scheme 2). ${ }^{[12]}$ 


$$
\text { Previous work by us: }
$$

Scheme 2. Previous works in activation of heterocycles and new synergistic approach for the synthesis of dihydroacridines.

In this communication, we report the first example of enantioselective version of the synthesis of 3,4-dihydroacridines 8 via synergistic catalysis. Starting from quinoline derivative 5 , the addition of a metal Lewis acid, which coordinates the aromatic nitrogen, increases the acidity of the $\alpha$-methylene and thus enhance its nucleophilicity. Next, the enal 6 reacts with the chiral secondary amine catalyst $\mathbf{7}$ to form the iminium ion that facilitates the conjugated addition by the nucleophile. The enolate intermediate formed "in situ" undergoes an intramolecular aldol reaction with the strategically located carbaldehyde, through a 6exo-trig cyclization, to form the six-membered ring. Finally, the dehydration renders the desired dihydroacridine $\mathbf{8}$. Advantages of the present protocol is the use of simple Lewis acid without the need of expensive ligand for the carbon activation as well as with the stereochemical discrimination coming from the chiral amino catalyst.

We started to study the reaction between 2-methylquinoline-3carbaldehyde and 4-nitro-cinnamaldehyde. The best conditions involve the use of the TMS-protected diphenyl prolinol 7 as chiral organocatalyst and $\mathrm{Yb}(\mathrm{OTf})_{3}$ as a metal Lewis acid with o-nitro benzoic acid as additive in dichloroethane (DCE), rendering the product 8 a in $75 \%$ yield and $94 \%$ ee (see Supporting Information $=\mathrm{SI})$. We then studied the scope of the reaction, testing differently substituted aromatic $\alpha, \beta$-unsaturated aldehydes 6 (Scheme 3). The reaction works well with different electron-withdrawing group (EWG), electron-donating group (EDG) and halogen substituents at the para-position of the enal 6, giving the products in $57-75 \%$ yields and high enantioselectivity (82-94\% ee, 8a-f and $8 \mathrm{~h}$ ). Unsubstituted cinnamaldehyde afforded the dihydroacridine $\mathbf{8 g}$ in good yield and up to $96 \%$ ee. Similar results were obtained when EWG, EDG and halogen are placed on the ortho-position of the enal (8k-m). However, lower yield was achieved with metabromo-cinnamaldehyde while still maintaining high enantioselectivity (8j). The reaction was successfully expanded to a more sterically demanding 2-naphthyl cinnamaldehyde, isolating the dihydroacridine $\mathbf{8 n}$ with good yield and high enantioselectivity. Furthermore, the heteroaromatic substituted enal can also be converted to the desired product in high ee value, as in the case of 2 -furyl substituted dihydroacridine $\mathbf{8 0}$, albeit in moderate yield. When an aliphatic enal was tested, high ee was obtained but with only $26 \%$ yield (8p), so no other aliphatic enal was explored further (Scheme 3). The reaction was tested on $2 \mathrm{~g}$ scale of 2-methylquinoline-3-carbaldehyde and the product $8 \mathbf{a}$ was obtained in $49 \%$ yield.

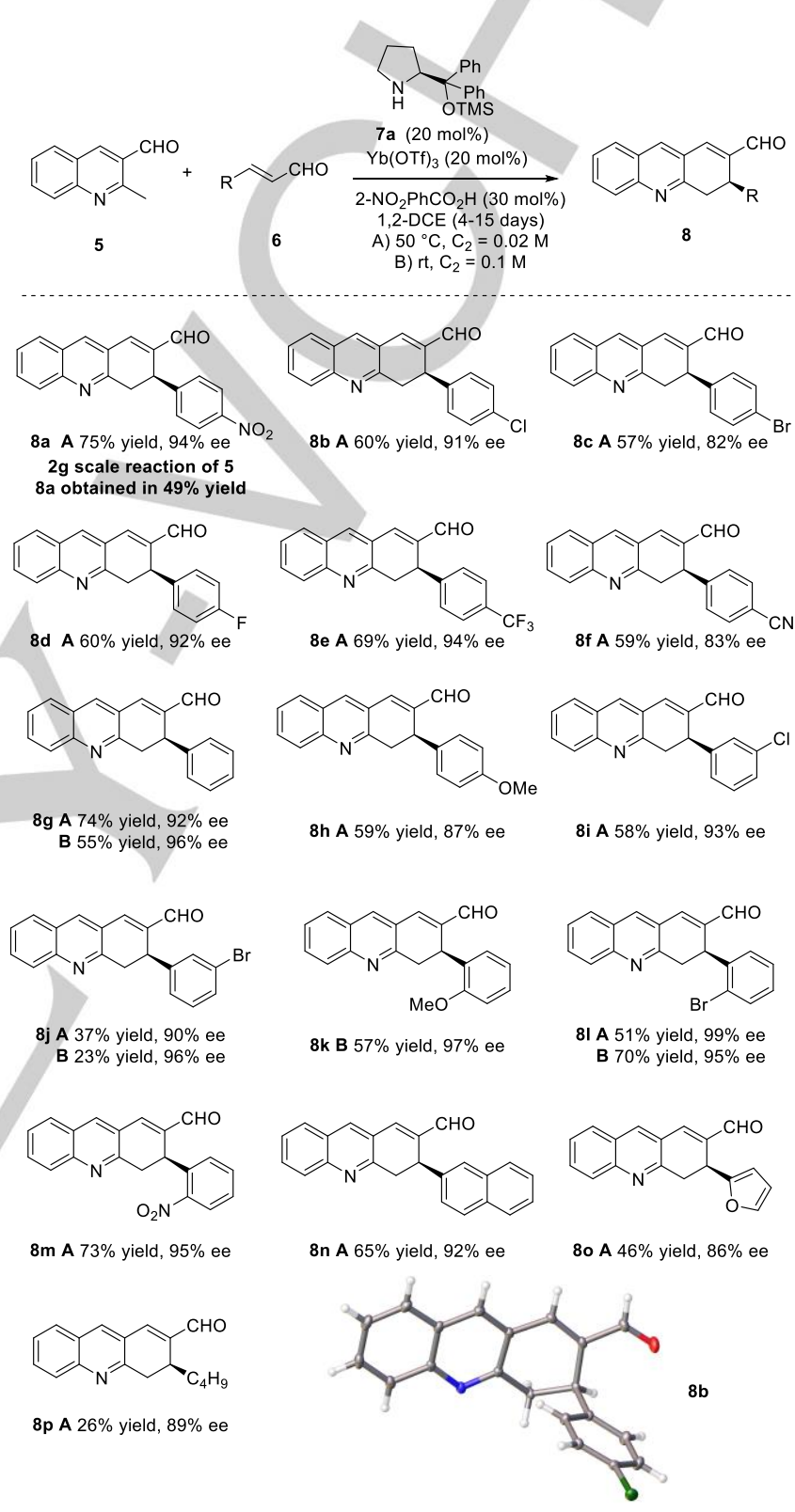

Scheme 3. Reaction scope of quinoline 5 and $\alpha, \beta$-unsaturated aldehydes 6 . Yields of isolated products. The ee was determined by chiral HPLC analysis. The reactions were performed on a $0.1 \mathrm{mmol}$ scale.

Substituted quinoline derivatives $\mathbf{5}$ gave, in all cases, high enantioselectivities $(88-96 \%$ ee) (Scheme 4$)$. When chlorosubstituent was present in the 7-position or in 6- and 8-positions of the quinoline, moderate yields were observed (8q-s) while methyl-substituent in 6-position or fluoro-substituent in 5-position gave the desired products ( $8 \mathrm{t}$ and $8 \mathbf{u}$ ) in $69 \%$ and $64 \%$ yields, respectively. 
The reaction was expanded to longer chain at the 2-position of the starting quinoline in order to obtain dihydroacridines with two new stereocenters. The new stereocenter epimerizes during the column chromatography, allowing getting the thermodynamic compound. As can be seen in the table, when bigger is the substituent in the 2-position of the starting quinoline, better is the diastereomeric ratio. In the major part of the examples, the minor diastereomer was not detected after the column chromatography.

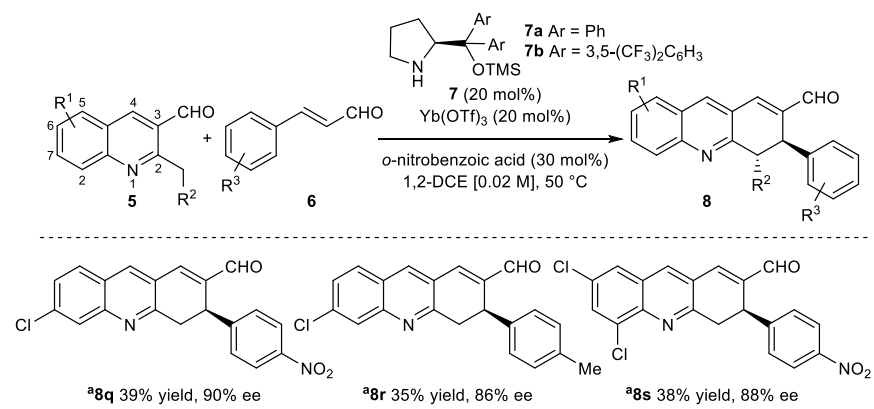<smiles>Cc1ccc2nc3c(cc2c1)C=C(C=O)[C@H](c1ccc([N+](=O)[O-])cc1)C3</smiles>

ast $69 \%$ yield, $94 \%$ ee ${ }^{a} 8 \mathrm{u} 64 \%$ yield, $95 \%$ ee

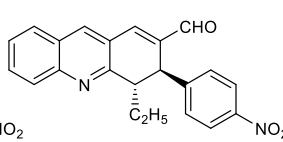
$8 \mathrm{v} 78 \%$ yield (major), $94 \%$ ee $15 \%$ yield (minor)<smiles>O=CC1=Cc2cc3ccccc3nc2[C@H]([Hg])[C@@H]1c1ccc([N+](=O)[O-])cc1</smiles><smiles></smiles><smiles>O=CC1=Cc2cc3ccccc3nc2[C@H]([18OH])[C@@H]1c1ccc(Cl)cc1</smiles>

8w $72 \%$ yield (major), $96 \%$ ee $8 \times 75 \%$ yield (major), $90 \%$ ee 8 y $40 \%$ yield (major), $84 \%$ ee $18 \%$ yield (minor)

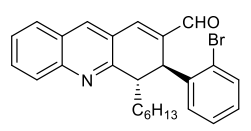

$8 \mathbf{z} 46 \%$ yield (major), $80 \%$ e日

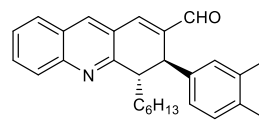

8 aa $48 \%$ yield (major) $84 \%$

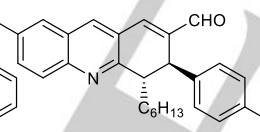

bab $80 \%$ yield (major/minor) $96 \%$ ee (major) $\mathrm{NO}_{2}$ unsaturated aldehydes 6 . Yields of isolated products. The ee was determined by chiral HPLC analysis. The reactions were performed on a $0.1 \mathrm{mmol}$ scale. a) Catalyst $7 \mathbf{a}$ was used, in the other entries $\mathbf{7 b}$ was used. b) Isolated as an inseparable mixture of diastereomers, dr: 6:1.

The dihydroacridine products $(8 \mathrm{v}-8 \mathrm{ab})$ with ethyl, propyl and hexyl substituents were isolated in moderate to high yields $(40 \%$ to $80 \%$ yield) with high enantioselectivities ( $80 \%$ to $96 \%$ ee) (Scheme 4).

The absolute configuration of product $\mathbf{8 b}$ was assigned by X-ray crystallography, ${ }^{[13]}$ while the absolute and relative configuration of product $\mathbf{8} \mathbf{x}$ was inferred by 2D NMR spectroscopy (see SI). The other structures were assigned by analogy.

To illustrate the high potential of this reaction, several useful transformation of dihydroacridine products $(8 \mathrm{~m}$, ent-8m, $8 \mathrm{~g}$ and 8c) have been devised (Scheme 5). For example, the reduction of $8 \mathrm{~m}$ with sodium borohydride provided the corresponding product 12 in high yield (85\%). The Wittig reaction of ent-8m rendered $\alpha, \beta$-unsaturated ketone 13 in $72 \%$ yield and reductive amination between aldehyde $\mathbf{8 g}$ and benzylamine $\mathbf{1 0}$ gave the desired product 14 in $58 \%$ yield. Moreover, the bromo-substituted dihydroacridine $\mathbf{8 c}$ was used in a Suzuki reaction, leading to the target product 15 in $47 \%$ yield (Scheme 5). It is noteworthy that the enantiopurity of the diverse products was perfectly maintained during the organic transformations in all cases.

To shed light on the synergy exerted by the combination of a Lewis acid and an organocatalysts, we carried out a detailed computational study mainly directed to understand the pathway operating in the synergistic. DFT calculations with ytterbium require relativistic effective core potentials adapted to the corresponding oxidation state that should be used in combination with its optimized basis set augmented by a polarization function. ${ }^{[14]}$
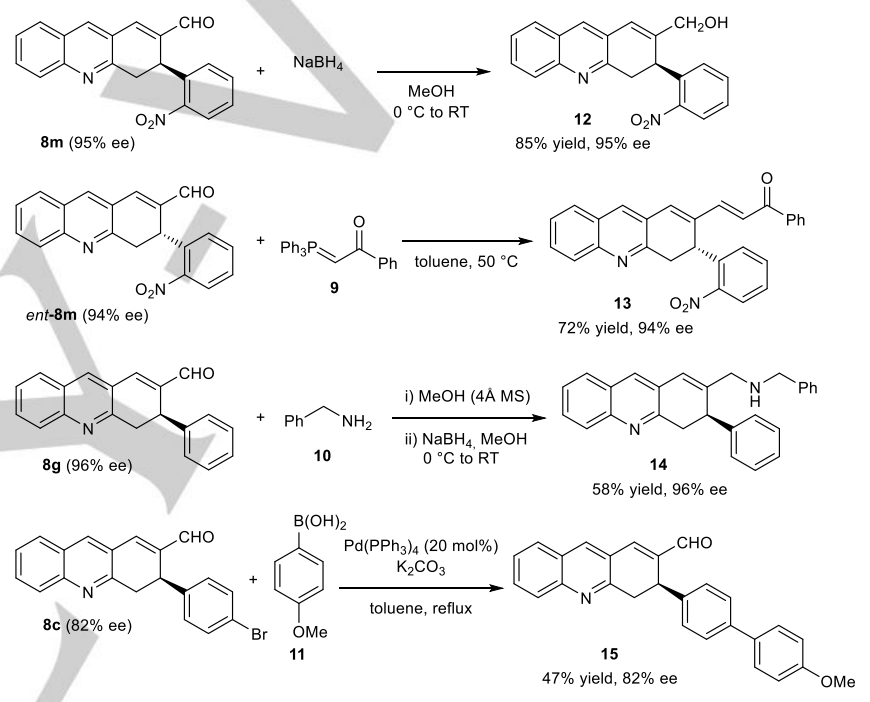

Scheme 5. Examples of derivatization of dihydroacridine products. Yields of isolated products. The ee was determined by chiral HPLC. The reactions were performed on a $0.1 \mathrm{mmol}$ scale.

Calculations with a minimum of accuracy for such large systems and considering the various reaction pathways are prohibitive in terms of computer time. Since similar results were obtained with indium (90\% ee and $19 \%$ yield, see SI, Table 1) we carried out calculations with $\ln (\mathrm{OAc})_{3}$ as Lewis acid. We use the B3LYP functional with dispersion correction and Ahlrichs' basis sets DEF2SVP and DEF2TZVP. Solvent effects were included in energy calculations (for details, see SI). Our mechanistic studies were based on two different cycles operating at organocatalytic and Lewis acid levels (Scheme 6). It is well-known that catalyst 7 operates following a typical steric model. ${ }^{[15]}$ Consequently, only the attack through the less hindered $R e$ face of the iminium has been considered in agreement with previous calculations for other similar reactions, ${ }^{[15]}$ not being necessary to include chirality in the pyrrolidine for unravelling the reaction mechanism. 


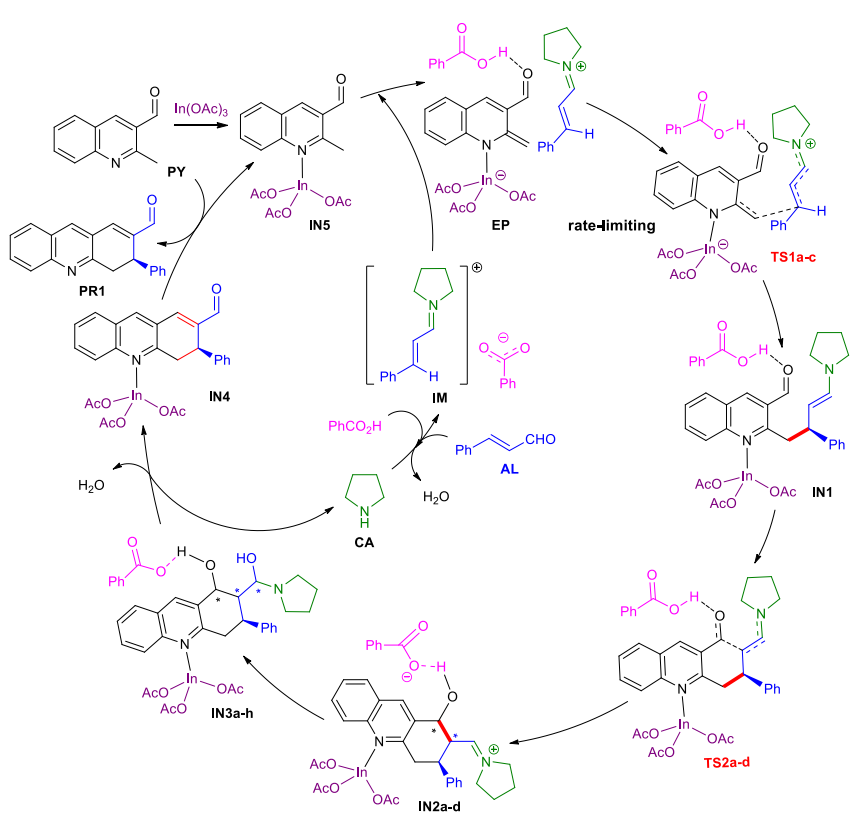

Scheme 6. Catalytic cycle.

Initially, after the Lewis acid activation of PY by forming IN5 and the formation of the iminium salt IM, the reaction commences with the development of the encounter pair EP. We have considered six approaches for the corresponding TS1 (see SI), the most stable showing an energy barrier of $5.5 \mathrm{kcal} / \mathrm{mol}$. After formation of (S)-IN1, as a consequence of the attack by the less hindered $R e$ face of the iminium salt, the ring closing leading to IN2 that can account through four different approaches depending on the attack by $\mathrm{Re} / \mathrm{Si}$ faces of the aldehyde and enamine functionalities. For this step, the presence of benzoic acid for activating the aldehyde is crucial. All the transition structures TS2 corresponding to the different approaches were more stable than TS1 thus confirming the formation of the new stereogenic center as the rate-limiting step. The most stable TS1 showed favorable London dispersion interactions between the aromatic rings as confirmed by a $\mathrm{NCl}$ analysis ${ }^{[16]}$ (Figure 2).
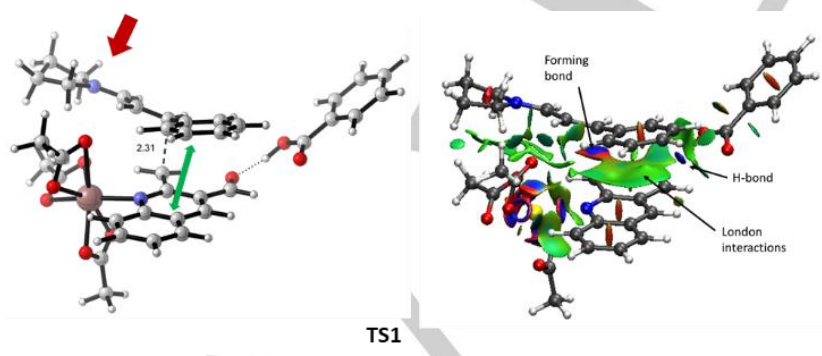

Figure 2. Most stable TS1 (rate-limiting step of the catalytic cycle). Left: Red arrow indicates the position of the bulky group at the original enantiopure catalyst. Green double arrow indicates favorable London interaction at the most stable transition structure. Right: $\mathrm{NCl}$ analysis confirming London dispersion interactions between the quinoline and the phenyl group.
The most stable TS2 corresponds to the approach between the $R e$ face of the aldehyde and the Si face of the enamine leading to $(S, S, R)$-IN2. Addition of water to IN2 yield IN3 generating more stereogenic centres (see SI) which are, however, irrelevant for the course of the reaction. After hydrolysis releasing the catalyst and benzoic acid, the dehydration also promoted by the acid, forms complex IN4. Exchange of the Lewis acid between IN4 and the starting material PY yields IN5 that, after combination with the newly formed iminium salt IM, produces EP starting a new catalytic cycle. The energy balance of the catalytic cycle illustrated in Scheme 6 is favourable in agreement with the energy profile and a driving force of $-2.4 \mathrm{kcal} / \mathrm{mol}$ (Figure 3).

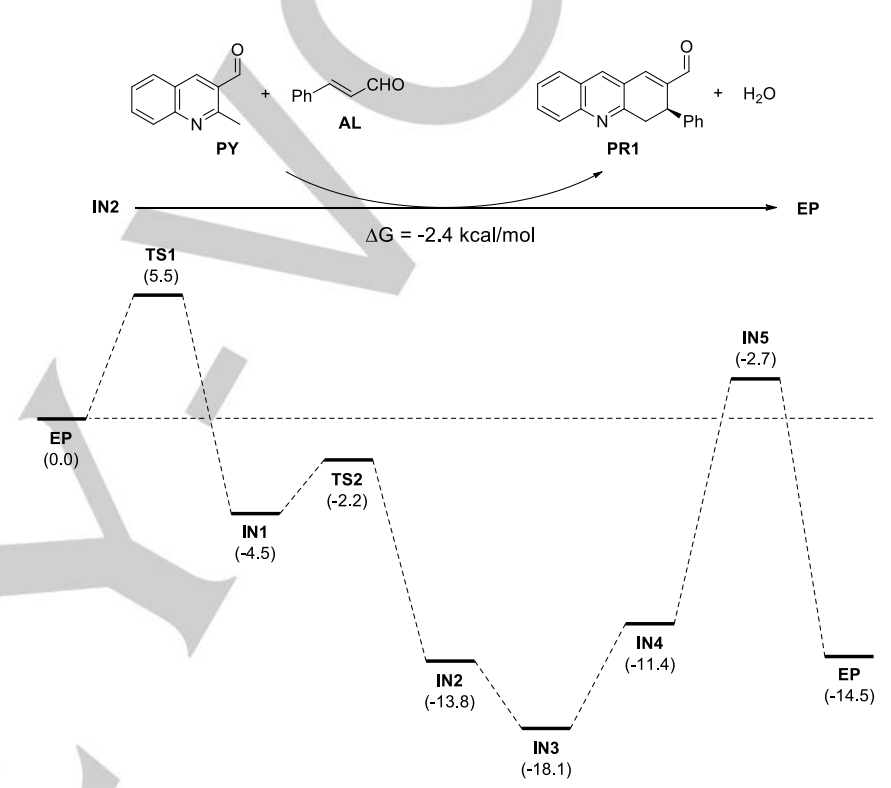

Figure 3. Energy profile for the catalytic cycle (the most favorable route is showed) and driving force.

In summary, we have reported a new synergistic methodology for the enantioselective synthesis of dihydroacridines with excellent results. This practical protocol is easy to perform and shows a broad substrate scope tolerating a range of functionalities with high enantioselectivity (up to $99 \%$ ee). The mechanistic studies revealed that the formation of the new stereogenic center as the rate-limiting step of the reaction and fully determined the synergistic cooperation between Lewis acid and organocatalyst though a double catalytic cycle.

\section{Experimental Section}

In a closed vial were added in this sequence: the organic catalyst $(R)$ - or

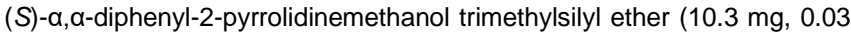
mmol, $20 \mathrm{~mol} \%$ ) or $(R)$ or (S)-a, a-bis[3,5-bis(trifluoromethyl)phenyl]-2pyrrolidinemethanol trimethylsilyl ether (17.9 mg, $0.03 \mathrm{mmol}, 20 \mathrm{~mol} \%), 2$ alkyl quinoline-3-carbaldehyde ( $0.30 \mathrm{mmol}, 2$ equiv), $\alpha, \beta$-unsaturated aldehyde ( $0.15 \mathrm{mmol}, 1$ equiv), ytterbium(III)trifluoromethanesulfonate (18.6 mg, $0.03 \mathrm{mmol}, 20 \mathrm{~mol} \%$ ), o-nitro-benzoic acid $(7.5 \mathrm{mg}, 0.045 \mathrm{mmol}$, $30 \mathrm{~mol} \%)$, and 1,2-dichloroetane $(7.5 \mathrm{~mL})$. The reaction mixture was stirred at $50^{\circ} \mathrm{C}$ and then monitored by ${ }^{1} \mathrm{H}$ NMR spectroscopy. 


\section{Acknowledgements}

S. M. and R. R. thank Accademia Nazionale dei Lincei for the RSC fellowship. M. M. and R. R. are grateful for EPSRC Core Capability Funding (EP/K039466/1). R. R. thanks Stephane Bidou, George Tsatsamis-Cooper and Andrew Howe for preliminary tests. T. T. and P. M. acknowledge the MINECO and FEDER Program (Madrid, Spain, project CTQ2016-76155-R) and the Gobierno de Aragon (Zaragoza, Spain. Biological and Computational Chemistry Group. E-34_17R). The authors thankfully acknowledge the resources from the supercomputers "Memento" and "Cierzo", technical expertise and assistance provided by BIFI-ZCAM (Universidad de Zaragoza, Spain).

Keywords: Acridine $\cdot$ Synergistic Catalysis • Enantioselective • Diastereoselective $\cdot$ Ytterbium

[1] a) C. Graebe, H. Caro, Ber. Dtsch. Chem. Ges. 1870, 3, 746-747; b) C. Graebe, H. Caro, Ann. Chem. 1871, 158, 265-281.

[2] J. Schmid, K. Jedlicka, US 537723 A.

[3] L. Benda, Ber. Dtsch. Chem. Ges. 1912, 45, 1787-1799.

[4] For an exceptional review on acridines, see: A. Schmidt, M. Liu, Adv. Heterocycl. Chem. 2015, 115, 287-353.

[5] M. Wainwright, J. Antimicrob. Chemother. 2001, 47, 1-13.

[6] G. Cholewiński, K. Dzierzbicka, A. M. Kołodziejczyk, Pharmacol. Rep. 2011, 63, 305-336.

[7] K. Krzymiński, A. D. Roshal, B. Zadykowicz, A. Białk-Bielińska, A. Sieradzan, J. Phys. Chem. A 2010, 114, 10550-10562.

[8] H. U. B. N. F. Tasleem, Int. J. Pharm. Pharm. Res. 2018, 11, 269-283.

[9] D. C. Rogness, R. C. Larock, J. Org. Chem. 2010, 75, 2289-2295.

[10] a) F. Lovering, J. Bikker, C. Humblet, J. Med. Chem. 2009, 52, 6752 6756; b) F. Lovering, Med. Chem. Commun. 2013, 4, 515-519.
[11] a) M. Meazza, G. Sitinova, C. Poderi, M. Mancinelli, K. Zhang, A Mazzanti, R. R. Torres, Chem. Eur. J. 2018, 24, 13306-13310; b) M. Meazza, M. Potter, M. B. Pitak, S. J. Coles, A. Mazzanti, R. Rios, Eur. J. Org. Chem. 2017, 719-725; c) M. Meazza, M. E. Light, A. Mazzanti, R. Rios, Chem. Sci. 2016, 7, 984-988; d) M. Meazza, V. Ceban, M. B. Pitak, S. J. Coles, R. Rios, Chem. Eur. J. 2014, 20, 16853-16857.

[12] M. Meazza, F. Tur, N. Hammer, K. A. Jørgensen, Angew. Chem. Int. Ed. 2017, 56, 1634-1638; Angew. Chem. 2017, 129, 1656-1660.

[13] CCDC 1899024 (compound 8b) contains the crystallographic data for this paper. This data is provided free of charge by The Cambridge Crystallographic Data Centre.

[14] a) X. Liu, L. Xiang, E. Louyriac, L. Maron, X. Leng, Y. Chen, J. Am. Chem. Soc. 2019, 141, 138-142; b) M. Dolg, H. Stoll, A. Savin, H. Preuss, Theor Chim. Acta 1989, 75, 173-194.

[15] a) M. Marigo, T. C. Wabnitz, D. Fielenbach, K. A. Jørgensen, Angew. Chem. Int. Ed. 2005, 44, 794-797; Angew. Chem. 2005, 117, 804-807; b) Y. Hayashi, H. Gotoh, T. Hayashi, M. Shoji, Angew. Chem. Int. Ed. 2005, 44, 4212-4215; Angew. Chem. 2005, 117, 4284-4287; c) Y. Hayashi, D. Okamura, T. Yamazaki, Y. Ameda, H. Gotoh, S. Tsuzuki, T. Uchimaru, D. Seebach, Chem. Eur. J. 2014, 20, 17077-17088; d) B. S Donslund, T. K. Johansen, P. H. Poulsen, K. S. Halskov, K. A. Jørgensen, Angew. Chem. Int. Ed. 2015, 54, 13860-13874; Angew. Chem. 2015, 127, 14066-14081; e) S. Meninno, A. Lattanzi, Chem. Commun. 2013, 49, 3821-3832; f) A. Orue, U. Uria, D. Roca-López, I. Delso, E. Reyes, L. Carrillo, P. Merino, J. L. Vicario, Chem. Sci. 2017, 8, 2904-2913; g) V. Juste-Navarro, L. Prieto, I. Delso, R. Manzano, T. Tejero, E. Reyes, J. L. Vicario, P. Merino, Adv. Synth. Catal. 2017, 359, 4122-4128.

[16] a) E. R. Johnson, S. Keinan, P. Mori-Sánchez, J. Contreras-García, A. J. Cohen, W. Yang, J. Am. Chem. Soc. 2010, 132, 6498-6506; b) J. R. Lane, J. Contreras-García, J.-P. Piquemal, B. J. Miller, H. G. Kjaergaard, J. Chem. Theory Comput. 2013, 9, 3263-3266. 
Layout 2:

\section{COMMUNICATION}

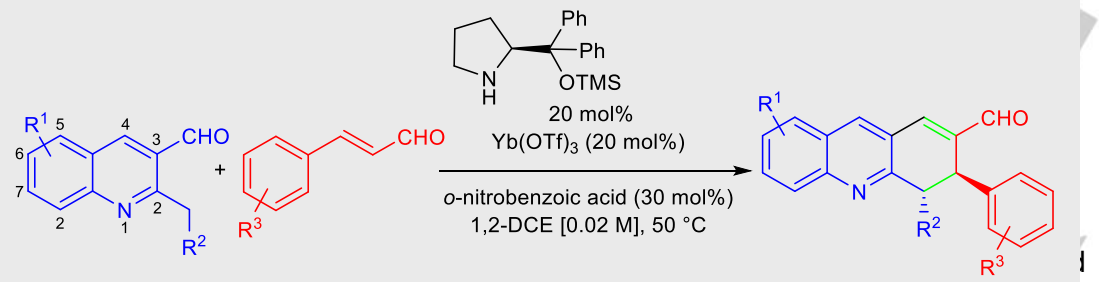

Sara Meninnol Marta Meazza ${ }^{*}$ Jung Woon Yang, Tomas Tejero, Pedro Merino $^{*}$ Ramon Rios ${ }^{*}$

Page No. - Page No.

Synergistic Catalysis: Highly Enantioselective Cascade Reaction for the Synthesis of Dihydroacridines

cascade reacrion the dihydroacridines in good yields and excellent stereoselectivities. 